\title{
EDUCAÇÃO, TECNOLOGIA EDUCACIONAL, SUBJETIVIDADE E HETERONOMIA
}

\author{
César Andrade(2)
}

RESUMO: Este trabalho problematiza a tendência, hoje dominante, que vincula a qualidade da Educação à utilização de recursos didáticos decorrentes das novas tecnologias educacionais. Busca-se, aqui, contrapor a essa tendência uma outra, que se coloca enquanto anormalidade ao que constitui a norma vigente do autoritarismo pedagógico subjacente a essa tendência. Busca-se indicar uma didática outra, engendrada no interior de uma concepção teórico-metodológica que se pretende emancipatória, aberta ao novo, à experiência, à reflexão.

Palavras-Chave: Educação e Tecnologia; Didática; Autoritarismo e Emancipação.

\section{EDUCAÇÃO, IMAGEM E REALIDADE: SOB O ENCANTO MIDIÁTICO}

Os processos educativos formais - desde os conteúdos a ensinar, até a didática subjacente aos diversos projetos político-filosóficos que a animam - e os sujeitos que deles participam atravessam, na atualidade, seu momento de maior crise.

Nunca se pôs em questão a centralidade da escola enquanto espaço de múltiplas possibilidades de formação tal como se tem feito na época presente. Do mesmo modo, não se havia atribuído aos processos formais de educação tamanha relevância para a constituição de uma sociedade em que as contradições e as desigualdades sociais pudessem ser equacionadas pela via da concretização de um projeto educativo/formador que se afirma emancipatório. Várias são as proposições e práticas que se anunciam como tendo em seu horizonte essa perspectiva $e$, dentre essas, uma parece estar alcançando status de prática hegemonicamente dominante: a da introdução das chamadas novas tecnologias educacionais. É sobre essa introdução que volto meu olhar, neste ensaio, buscando tecer reflexões acerca do que, aqui, denomino de "zona de entropia" do discurso, ou seja, aquele(a) espaço/relação/prática em que se chocam/anulam/refazem o dizer e o fazer. É nessa zona de entropia que, quer me parecer, podemos situar a temática proposta neste trabalho. E, exatamente por animar controvérsias muitas, não nos é mais possível pensar a didática alheios a essa tendência, que, com um vigor inexpugnável, avança veloz e ferozmente sobre o campo educacional e as práticas aí desenvolvidas, as relações aí entrelaçadas. Diante dessa impossibilidade de ignorar o uso da tecnologia - em seus contornos contemporâneos - na educação, que questões podem dirigir a análise que se quer crítica do objeto em tela? Uma primeira poderia encontrar seu foco em uma aceitação, ou em uma recusa "pura" 
do uso da tecnologia, que, atualmente, se apresenta disponível em cascata aos que se dedicam à tarefa de educar.

De início, podemos nos reportar aos traços fundamentais da organização social hodierna, organização essa que "abriga" um determinado indivíduo, que pensa/age/pensa. Um terreno social e historicamente constituído é o solo sobre o qual se movem homens e mulheres, crianças e velhos.

Poder-se-ia, então, perguntar: quem é esse indivíduo? Que estrutura sociopolítica e econômica é essa em que ele se produz? Que tecnologia é essa que ele desenvolve e utiliza - ou seria mais próprio afirmar "e que por ela é utilizado"?

A afirmação do caráter social da condição humana implica o reconhecimento de que, quer materialmente, quer simbolicamente, a constituição do indivíduo se dá em determinado contexto histórico, em determinadas condições socialmente produzidas, condições emprenhadas de poder. Nessa perspectiva, que espécie de indivíduos vivenciam e produzem a contemporaneidade? Ou talvez devesse a pergunta estar invertida: que espécie de contemporaneidade produz as vivências dos indivíduos?

Viver, hoje, muito mais do que em qualquer outra época, é um misto de brilho e ofuscação.

Quem não se encanta com as façanhas do desenvolvimento tecnológico e de tudo o que ele pode propiciar em, praticamente, todos os âmbitos da vida em sociedade? Aeronaves que transportam indivíduos de um lado a outro do globo em horas; instrumentos laboratoriais e cirúrgicos, que desvendam o âmago do corpo $e$ nele intervém com precisão; microcomputadores que interligam indivíduos de Tókio a Belém. Por outro lado, quem não se choca com a miséria do viver atual? A violência nos centros urbanos cresce e assume traços de brutalidade cotidiana nunca antes vista; armas cada vez mais precisas e letais são fabricadas e penetram o corpo dos indivíduos em escala crescente; guerras modernas são travadas $e$ assistidas como a mais uma forma de entretenimento em milhões de lares, aumentando a audiência de canais de televisão globais; os avanços da medicina não chegam aos milhões de homens e mulheres excluídos daquela pequena parcela de indivíduos que por eles podem pagar; a fome e a desnutrição ainda matam seres humanos.

É no interior desta ambigüidade - contradição, no sentido dialético mesmo - que se movem os indivíduos. Uma contradição de caráter político, econômico e social que deita suas raízes na contradição anterior - a do capital versus trabalho -, que, na contemporaneidade, move-se mediada por uma racionalidade específica à hodierna organização societal: a racionalidade tecnológica, compreendida enquanto aquele modo de o indivíduo se relacionar com a realidade - com o outro $e$, até, consigo mesmo - assemelhado ao da racionalidade da organização do trabalho na fábrica. Não se afirma aqui uma transposição mecânica da organização fabril aos demais espaços em que os homens atuam. Antes, afirma-se uma 
interpenetração mediada por inúmeros mecanismos, que determinam, mutuamente, o fazer familiar, sindical, afetivo, educacional, fabril...

Uma racionalidade que a tudo antevê...

Uma das características mais profundamente determinantes de como as estruturas de poder entranham nos indivíduos, que, por sua vez, retroalimentam as estruturas da sociedade atual é a sobrevalorização do olho enquanto mediador da relação homem-mundo. É pelo olho que, de modo muito mais intenso, as coisas se nos chegam à consciências/inconsciência. A esse respeito, são interessantes as reflexões de Sodré (1994, p. 17), que, ao analisar o mito edipiano, desvela a vontade de submissão do outro presente na prevalescência, nos dias atuais, dos instrumentos midiáticos em todos os espaços/momentos/relações da vida de homens e mulheres. A pretensão de apreender a realidade por sua imagem, ao querer a tudo ver, nada de si se lhe chega, ao tentar ganhar a vida, perde a si mesmo.

... Narciso pode ser considerado como aquele que mata a verdade de si mesmo (sua realidade como indivíduo concreto) e morre em sua própria imagem, o seu duplo... Pós-modernamente, essa sedução converte-se em fascinação: o universo de vertigem narcísica, que caracteriza a ordem telerrealística da contemporaneidade, dá-se essa autonomia da ilusão, mas agora voltada para a operacionalidade da Organização.

Tudo nos chega pelos olhos; todas as informações tendem a ser reduzidas a um símbolo

No processo educativo formal, a penetração dessa racionalidade pode assumir caracteres graves, em se considerando que, também na escola, se constituem as identidades dos indivíduos. Se de um lado, a introdução das novas tecnologias educacionais contém elementos que possam tornar a aula um momento mais dinâmico - entendida a idéia de dinâmica no interior do momento histórico presente -, por outro, essa introdução deve ser encarada com uma certa cautela, cautela que reivindica o momento do questionar, que pode ser assim delineada: não estariam os dispositivos pedagógicos atuais - e que constituem, ao lado da técnica, a tecnologia educacional - assumindo papéis tendencialmente reprodutores da ordem vigente, da identidade hegemônica neoliberal, que submete a capacidade reflexiva dos indivíduos à mera aparência das coisas, da realidade?

Nesse jogo (mortal) da imagem com o real, o olho fica em primeiro plano em primeiro plano de importância, afirma Sodré (1994, p. 17), ao analisar a vontade edipiana que permeia o pensamento ocidental de a tudo ver - inclusive, na completa obscuridão, como ocorre com a face reificada da razão iluminista. Em tempos atuais, o olho, assumindo papel de "estômago da mente", devora imagens que se lhe apresentam, em velocidade e quantidade cada vez maiores, saturado de informações, que, afinal, não superam a si mesmas, por não conter em si a predisposição à reflexão, na medida em que são, cada uma em sua particularidade, um todo e respondem, no lugar do ouvinte, ao "quem, quando, como, onde, por quê". 
Dessa mesma onipotência edipiana alimenta-se a civilização ocidental, que "arma" o olho - funcionalizando-o em termos eficazes - de todos os recursos possíveis, para se investir da veleidade de visão universal (op. cit., p. 17)

Sem pretender analisar em profundidade as análises frankfurtianas acerca da conversão do esclarecimento em mito, pode-se afirmar que, na sua tentativa de superar o mito enquanto explicação da realidade, ao reduzir o particular, o individual à condição de secundário em relação à totalidade, o esclarecimento torna-se, ele próprio, mito e converte-se, na atualidade, em mecanismo de submetimento da capacidade de reflexão de homens e mulheres àquela visão pseudoconcreta da realidade, em que, parafraseando Larrosa (2002), extasiado de informações, o indivíduo, hoje, nada sabe, por que nada se lhe experimenta.

\section{A DIDÁTICA E AS NOVAS TECNOLOGIAS EDUCACIONAIS: ENTRE HOMENS E MÁQUINAS OU DO SUJEITADO}

As questões postas até aqui nos auxiliam a delimitar a inserção das novas tecnologias educacionais, mais especificamente, os uso de equipamentos eletromecânico e de informática - tais como o retroprojetor, o datashow e similares - , que se afirmam como instrumentos para a melhoria da qualidade do ensino.

Até aqui, vimos que não se pode compreender a atualidade dessa inserção sem situá-la no contexto histórico-social em que ela se apresenta. Vimos, igualmente, que é exatamente em virtude de refletir as configurações do atual ordenamento societal, que, ao supervalorizar o olho enquanto instrumento mediador da relação do indivíduo com a realidade que lhe é exterior, exacerba o apelo visual no processo de construção do conhecimento, inundando homens e mulheres com imagens de diferentes matizes e diferentes mensagens, deixando pouca margem de autonomia ao sujeito para a produção de sua própria interpretação dos objetos que se lhe chegam. Advogados dessa inserção não se fazem ausentes, antes, apressam-se em hiperdimensionar - chegando a marcar com contornos ideológicos suas defesas do uso do computador no ensino.

Neste contexto repensar a educação tem sido realizada por intermédio da introdução do computador na escola, tirando da inércia o processo de ensino aprendizagem, elevando o nível de valorização do professor junto a sociedade, buscando a eliminação da exclusão, imposta por condições sócio-econômicas, apoiando processos de raciocínios mais complexos, estimulando a motivação e a auto estima, favorecendo mudanças na estrutura escolar (Bianconi 2004).

Acusar a escola de inércia, do modo como o faz a citação acima, parece ter como objetivo a desqualificação das práticas educativas que se desenvolvem - ou que se desenvolviam, como parece ser a opinião do autor, pois que já existiriam todas as condições materiais concretas para a aplicação de um determinado modo de ensinar e de aprender socialmente justo - nas instituições de ensino julgadas obsoletas. Como se todas as alternativas já tivessem sido levadas a cabo $e$ fracassado, seria chegada a hora de a escola render-se ao poder formativo das 
máquinas, tais como os retroprojetores ou, no gosto mais moderno, dos messiânicos data shows.

\section{A AULA: NOVAS FACES DO AUTORITARITARISMO PEDAGÓGICO?}

Se o olho é o órgão mediador da relação homem mundo por excelência, na cultura ocidental, podemos perceber, aí, um lugar de contato entre as estratégias que norteiam as ações de homens e mulheres em sua luta cotidiana pela manutenção da vida no ambiente hostil das regras capitalistas de organização societal e as estratégias de ensino e aprendizagem no âmbito da escola, em particular, das instituições que se dedicam a educar os educadores, ou, em termos mais atuais, a formar os professores.

E onde e em que medida sociedade e educação se entrelaçam, se roçam? Que práticas podem denunciar essa cumplicidade, que, afinal, retorna a afirmar a ingenuidade do discurso que atribui papel exacerbado à educação no que se refere à eliminação - ou ao menos o arrefecimento das desigualdades sociais e das submissões todas?

Busco na estante da memória algumas lembranças...

Uma delas, muito recente, diz de um fenômeno que se repete com uma precisão quase matemática: ao indagar os discentes por que matricularam-se na disciplina Introdução à Educação(3), tenho como resposta, na quase totalidade dos alunos, algo como "por que está na grade curricular e por que penso que vai me ensinar a ensinar"... Uma outra, que remonta aos idos do final da década de 1990, nas disciplinas de Didática e Didática Geral, que constituíram-se de amontoadas tentativas de simular, através de dinâmicas e técnicas pedagógicas - o varal, matemática ilustrada, dramatizações de forte apelo visual - futuras aulas, futuros temas que encontraríamos nas escolas em que trabalharíamos. Em relatos atuais de discentes do curso de pedagogia, o uso de retroprojetores e data shows aparece como instrumento indispensável, sem o qual, as aulas não puderam, em diversas oportunidades, ser realizadas.

O que há de comum entre estas vivências de escolarização?

De início, elas indicam o quanto a tecnologia educacional se faz presente no cotidiano das salas de aula, bem como revela o vínculo entre o uso da tecnologia em educação e a organização da produção social, que pode ser percebido na afirmação de Bianconi (2004):

O mundo caminha a passos largos, diminuindo distâncias entre os seres, fato este que está levando os seres a uma contextualização do futuro acontecendo hoje, surgindo um novo paradigma educacional, que sugere a escola como ambiente criado para uma aprendizagem, rica em recursos, possibilitando ao aluno a construção do conhecimento a partir de uma individualização estilística de aprendizagem; [...] A informática está entrando na educação pela necessidade de 
se transpor as fronteiras do educar convencional, pois tudo que se modernizou na educação até o advento da informática se tornou convencional, frente a esta nova forma pedagógica de educação, oportunizando às escolas uma nova forma de trabalhar os conteúdos programáticos, propiciando ao educando, eficiência na construção do conhecimento, convertendo a aula num espaço real de interação, de troca de resultados, adaptando os dados à realidade do educando.

Destaco, inicialmente, da citação acima, a relação a que me refiro, qual seja, a de que, dadas as vertiginosas alterações no mundo do trabalho, a educação escolar repensa e refaz, de acordo com Bianconi (2002), seus paradigmas, resignifica o papel da escola, enquanto um espaço propício à construção do conhecimento.

Mas até que ponto essa relação de pertença entre sociedade e educação, que implica na resignificação do lugar que a escola ocupa no contexto da organização social mais ampla, bem como o uso da tecnologia agarrada aos parâmetros da lógica capitalista de produção, não se colocam exatamente como os obstáculos à construção de um ambiente favorável à construção do conhecimento?

Aqui, penso que pode ser delimitado, precisamente, o foco deste ensaio.

Em linhas gerais, se o olho é a mediação primal na relação homem-mundo e tem permitido sua apreensão, sua subjetivação, é pelo olho que ele (indivíduo) torna-se escravo das avalanches de imagens e mensagens que se lhe chegam à subjetividade. Se, ao nos acostumar a receber o mosaico pronto, montado, sem a necessidade "incômoda" do exercício do pensar, soterramos a reflexão(4), então, interpor entre o aluno e o autor de determinados conteúdos, projetados, por exemplo, por meio de um aparelho retroprojetor, pode assumir uma feição ambígua, periculosa mesmo para o desenvolvimento de uma consciência autonomamente emancipada. Uma nova face do autoritarismo? Autoritarismo pedagógico? Professores e alunos...

Diante do até aqui exposto, de que modo poder-se-ia visualizar o que aqui denomino autoritarismo pedagógico, mesmo no interior de um projeto políticoeducativo que se propõe emancipatório?

As palavras de Larrosa (2002, p. 21) aqui me auxiliam:

A experiência é o que nos passa, o que nos acontece, o que nos toca. Não o que se passa, não o que acontece, ou o que toca. A cada dia se passam muitas coisas, porém, ao mesmo tempo, quase nada nos acontece. Dir-se-ia que tudo está organizado para que nada nos aconteça. Walter Benjamim, em um texto célebre, já observava a pobreza de experiência que caracteriza o nosso mundo. Nunca se passaram tantas coisas, mas a experiência é cada vez mais rara.

A experiência é cada vez mais rara... 
E o professor que vai à aula todos os dias? Que encontra seus alunos todos os dias? O que seria isso que ele faz? Não estaria ele ensinando? E o aluno? Não estaria ele vivenciando uma experiência de estudar, de aprender?

Arrisco...

O professor, que, ancorado em profundas análises teóricas acerca da psicologia da aprendizagem, das técnicas pedagógicas mais eficazes, das formas mais eficientes de gestão do ambiente escolar, planeja a aula, minuto a minuto; que pensa com cuidado e minúcia cada unidade de seu plano de aula, da articulação precisa entre o conteúdo e a forma didática de ensiná-lo... enfim, tem a sala e tudo o que nela há nas mãos... Não estaria ele envolvido com seu trabalho? Na perspectiva que, aqui aponto, a resposta seria negativa. E por que não? Retomando o mito de Narciso, que mesmo na cegueira pretendia a tudo ver, assim também somos levados a tudo antever, a (pré)ver. O espaço do inesperado, do imprevisto, da novidade que é a aula, de encontro de subjetividades e materialidades, de histórias de vida diversas, múltiplos mundos, tende a ficar obliterado, enclausurado na racionalidade planificadora. Assim, se tenho em uma folha transparente, ou num disco magnético, o conteúdo fixado e planejo a aula em torno desses materiais, tendo a aprisionar a dinamicidade do encontro, do diálogo $e$, por conseguinte, a possibilidade de construções reflexivas outras, diversas da minha... Coisas que eu não havia pensado tendem a não "emergir" e eu, tendencialmente, torno o outro idêntico a mim. Autoritarismo?

O aluno, sentado em sua cadeira de escola, atento à parede iluminada, refletindo o conteúdo... Este, por sua vez, ao fixar sua atenção à imagem, tende a resignar-se, a conformar-se com o pronto, tendendo a minimizar o necessário esforço de reflexão... Autonomia?

Experiência... Cada vez mais rarefeita...

Finalizo, aqui, ressalvando que, ao expor as reflexões que venho desenvolvendo a partir de minha prática docente e discente, não aponto para a ausência do pensar, do refletir, do avaliar nossa prática profissional, não advogo o espontaneísmo puro e simples. Muito menos professo uma possível saída para o que aqui indico como problema... Antes, espero que estes escritos possam, muito mais - e aí, penso, reside a contribuição deste ensaio -, propor um debate, uma reflexão, compartilhar inquietações, dialogar... Experimentar...

\section{REFERÊNCIAS}

BIANCONI, D.A. Educação e tecnologia: o professor sempre mestre. Disponível em $<$ http://www.bianconi-a.hpg.ig.com.br/educacao_e_tecnologa.htm > . Acessado em março de 2004.

LARROSA, J. Notas sobre a experiência e o saber de experiência. In: Revista Brasileira de Educação. São Paulo: ANPED. Jan/fev/mar/abr, 2002, n. 19. 
SODRÉ, M. A máquina de Narciso. São Paulo: Cortez, 1994.

\section{NOTAS}

(1) Ensaio, inicialmente, publicado nos anais do XII Encontro Nacional de Didática e Prática de Ensino e reformulado para atender às exigências editorias da Revista Sul-Americana de Filosofia e Educação.

(2) Discente do Programa de Estudos Pós-Graduados em Serviço Social, da Universidade Federal do Pará,. E-mail cesar-andrade30@bol.com.br.

(3) Disciplina do chamado "conjunto de disciplinas pedagógicas", ofertada aos cursos de licenciatura e que habilitam os bacharéis para o magistério do ensino fundamental e médio.

(4) Lembro, aqui, um jargão da ciência da propaganda, que se tem usado como justificativa para o uso da publicidade como quintessência do sucesso de uma dada empreitada empresarial: "uma imagem vale mais do que mil palavras". 